\title{
ABORTAMENTO DE GEMAS FLORAIS DE CINCO CULTIVARES DE PEREIRA (Pyrus spp., L.) EM DOIS LOCAIS DO RIO GRANDE DO SUL ${ }^{1}$, BRASIL
}

\author{
FLOWER BUD ABORTION IN FIVE PEAR CULTIVARS (Pyrus spp., L.), \\ IN TWO LOCALITIES OF RIO GRANDE DO SUL, BRASIL
}

\author{
João José Pinto de Arruda ${ }^{2}$, Darcy Camelatto ${ }^{3}$
}

RESUMO

O abortamento de gemas florais é um dos principais problemas verificados nos pomares de pereira no Brasil. Caracteriza-se pela presença de necrose nos primórdios florias das gemas, e ocasiona grande diminuição do potencial produtivo. $O$ trabalho objetivou avaliar a ocorrência do abortamento nos cultivares Packham's Triumph, Bartlett, Red Bartlett (Pyrus communis, L.) e Século XX (Nijisseiki) e Shinseiki (P. pyrifolia, [Burm.] Nak.), de gemas coletadas em Vacaria e Veranópolis, no RS. As análises foram realizadas nos laboratórios da Embrapa/CPACT, em Pelotas - RS. As amostras de gemas florais foram coletadas em três épocas (23 de abril de 1994, 03 junho de 1994 e 25 de junho de 1994) e observadas internamente com microscópio. Observou-se que as gemas florais da cv. Packham's Triumph apresentavam maiores porcentagens $(38,84 \%)$ de primórdios necrosados em relação aos demais cultivares, seguido das cvs. Bartlett (10,74\%) e Red Bartlett (7,11\%). As cvs. Século XX e Shinseiki, apresentaram menor número de primórdios necrosados $(1,49$ e $0,80 \%$, respectivamente), em comparação aos demais cultivares. Quanto ao local, as gemas coletadas em Veranópolis apresentaram maior número de primórdios necrosados do que as coletadas em Vacaria, e, para época, as gemas coletadas em 25 de junho, apresentaram intensidades de primórdios necrosados superiores às coletadas em 23 de abril e 03 de junho.

Palavras-chave: pereiras, abortamento floral, necrose de gemas, morte de gemas.

\section{SUMMARY}

Floral bud abortion has been one of the main problems of the pear orchards in Brazil. This problem is characterized by occurrence of necrosis in flower primordia of floral buds decreasing the potential of productivity of the crop. This research was carried out at EMBRAPA/CPACT, Pelotas, RS,

\begin{abstract}
aiming to evaluate the occurrence of flower bud abortion in pear trees of Pyrus communis, L., cvs. Packham's Triumph, Bartlett and Red Bartlett and Pyrus pyrifolia [Burm.] Nak. cvs. $20^{\text {th }}$ Century (Nijisseiki) and Shinseiki, collected in two locals of Rio Grande do Sul. The samples of flowers buds was collected in three times: April 23, June 03 and June 25 and observed inside by mycroscope. The highest percentage of necrotic primordia that occured until June 25, was observed in the buds of Packham's Triumph (38.84\%) followed by primordia observed in the trees of the two japanese cultivars 'Nijisseiki' and 'Shinseiki' (1.49\% and $0.80 \%$, respectively). Regarding to the places, there was higher incidence offlower bud abortion in Veranopolis than in Vacaria.
\end{abstract}

Key words: pear trees, floral abortion, bud necrosis, bud death.

\section{INTRODUÇÃO}

A produção de pêras no Brasil não tem expressão em nível mundial. A pereira no Brasil é, dentre as frutíferas de clima temperado, aquela em que não ocorreu o desenvolvimento de grandes áreas de produção, ficando restrita a plantios inexpressivos do ponto de vista comercial (MAIA et al., 1996). Segundo NAKASU \& LEITE (1990), dentre as frutas de clima temperado, a pêra é a terceira mais consumida no Brasil, sendo superada pela maçã e o pêssego. Isso evidencia o potencial de mercado na Região Sul do Brasil, onde, dadas as condições climáticas, tem possibilitado o cultivo da macieira.

Existem dois grupos de pereiras cultivadas: pereiras européias (Pyrus communis), os principais cultivares são: Packham's Triumph, Bartlett (William's Bon Chrètien), Red Bartlett, Abate Fetel,

\footnotetext{
${ }^{1}$ Trabalho realizado na EMBRAPA/CPACT (Pelotas -RS); parte do trabalho do primeiro autor, para obtenção do grau de Mestre em Agronomia, UFPel - Faculdade de Agronomia Eliseu Maciel.

${ }^{2}$ Engenheiro Agrônomo, Mestre Bolsista DTI/CNPq - EMBRAPA/SPSB - GL-Canoinhas.

${ }^{3}$ Engenheiro Agrônomo, PhD., Pesquisador da EMBRAPA/CPACT, bolsista CNPq. 
Winter Nellis, Beurré Hardy; e as pereiras asiáticas (Pyrus pyrifolia), também conhecidas como pereiras orientais ou japonesas, cujos principais cultivares são: Século XX (Nijisseiki), Kosui, Hosui, Suisei e Shinseiki.

A cultura da pereira tem tido pouco desenvolvimento no Brasil devido à baixa produtividade das plantas, principalmente de cultivares europeus (CAMELATTO et al., 1997). As principais causas limitantes para a expansão da cultura são: falta de cultivares produtores de frutas de boa qualidade, adaptados às condições climáticas; indefinição de porta-enxertos; e o abortamento de gemas florais, que em alguns anos, dependendo do cultivar, atinge de 30 a $100 \%$ das gemas florais (NAKASU \& LEITE, 1992).

O abortamento de gemas florais caracterizase pela manifestação de necrose parcial ou total dos primórdios florais, acarretando na diminuição do potencial de floração. MONTESINOS \& VILARDELL (1996) consideraram que o abortamento floral de pereira é uma enfermidade que se manifesta pela destruição parcial ou total das gemas durante a dormência ou no período de brotação. As gemas afetadas apresentam as escamas protetoras dessecadas e os primórdios florais também dessecados ou necrosados (KINGSTON et al.,1990; MONTESINOS \& VILARDELL, 1991; NAKASU et al., 1995). A campo, as gemas florais apresentam escamas frouxas com a extremidade apical afastada da parte central e em laboratório, verifica-se a presença de primórdios necrosados vistos com microscópio ótico.

Problema semelhante de abortamento de gemas florais em pereiras foi também observado em outros países (MARODIN et al., 1996). Na Nova Zelândia, em pereiras asiáticas, a desordem varia grandemente entre plantas, cultivares, locais e anos (KINGSTON et al., 1990; KLINAC \& GEDDES, 1995).

Várias hipóteses têm sido formuladas para explicar esse fenômeno, tanto no Brasil como em outros países, tais como: insuficiência de frio hibernal; flutuações de temperatura no inverno; problemas nutricionais; doença (CAMELATTO et al., 1997). Mas, até o presente, nenhuma delas tem sido comprovada experimentalmente.

Várias observações da ocorrência de abortamento, durante o outono, indicam que a possível causa do abortamento de gemas florais de pereira inicia durante o período de verão e outono (fase de desenvolvimento das gemas florais), e que o desencadeamento do problema ocorre antes do inverno (ARRUDA, 1998).
Com o objetivo de avaliar a ocorrência de anomalias nos primórdios florais durante o outono e início de inverno, conduziu-se um experimento no qual foram examinadas gemas de cinco cultivares de pereiras (européias e asiáticas), coletadas em três épocas e em dois locais do Rio Grande do Sul (Veranópolis e Vacaria).

\section{MATERIAL E MÉTODOS}

No outono e inverno de 1994, foram coletadas amostras de gemas florais das pereiras européias (Pyrus communis, L.), cvs. Packham's Triumph, Bartlett e Red Bartlett, e asiáticas (Pyrus pyrifolia) cvs, Shinseiki e Século XX. Foram colhidas 10 gemas florais em Vacaria e 10 em Veranópolis, em 23 de abril de 1994, 03 junho de 1994 e 25 de junho de 1994, coletadas aleatoriamente ao redor da copa das plantas. Logo após colhidas, as gemas foram colocadas em frascos contendo FAA (solução de $10 \%$ formol, 5\% ácido acético e $85 \%$ álcool "70"), para preservar as partes das gemas.

Posteriormente, no laboratório, retiraram-se as escamas das gemas, e observando-se os primórdios florais, com uma lupa (10X), considerando-se como normais (primórdio floral sem necroses) e afetados (primórdio parcial ou totalmente necrosado).

Utilizou-se o delineamento inteiramente casualizado, seguindo um esquema fatorial $5 \times 2 \times 3$, com cinco cultivares (Packham's Triumph, Bartlett, Red Bartlett, Século XX e Shinseiki); dois locais (Vacaria e Veranópolis) e três épocas (23 de abril de 1994, 03 junho de 1994 e 25 de junho de 1994), com três repetições.

Para interpretação dos resultados foi feita análise de variância, e as médias dos tratamentos foram analisadas pelo teste de Duncan em nível de $5 \%$ de probabilidade. Os dados em porcentagem foram transformados em arco seno multiplicado pela raiz quadrada da porcentagem.

\section{RESULTADOS E DISCUSSÃO}

Não houve interação significativa entre os fatores avaliados. Houve efeito significativo do fator cultivar nos dois locais, Vacaria e Veranópolis, (figura 1), quanto a intensidade de abortamento de gemas florais de pereiras, no outono (23 de abril) e parte do inverno de 1994 (03 e 26 de junho). As gemas da cv. Packham's Triumph apresentaram porcentagens de primórdios necrosados $(38,84 \%)$ maior do que os demais cultivares. As gemas da cv. Red Bartlett apresentaram porcentagens equivalentes as da cv. Bartlett $(10,74 \%$ e $7,11 \%$, respectivamen- 


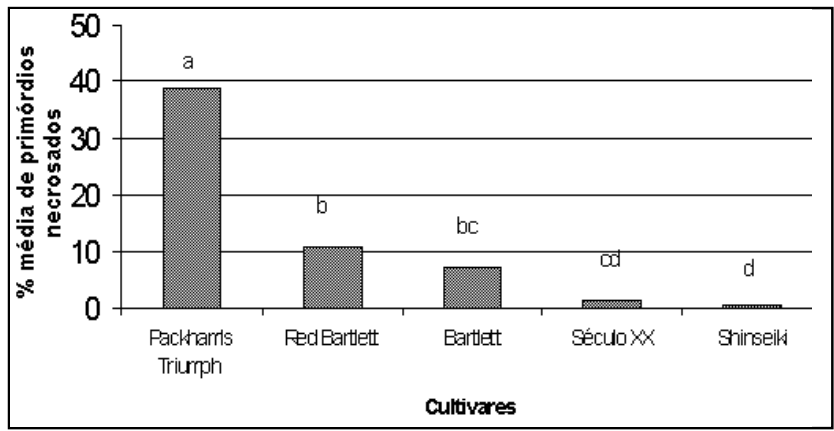

Figura 1 - Porcentagem de primórdios florais necrosados, em cinco cultivares de pêras em Vacaria e Veranópolis, Pelotas, RS, 1994.

* Médias seguidas por letras distintas diferem entre si em nível de $5 \%$ de probabilidade pelo teste de Duncan.

te), mas significativamente superiores as das cvs. Século XX e Shinseiki, as quais tiveram porcentagens de primórdios necrosados equivalentes $(1,49 \%$ e $0,80 \%$, respectivamente). Por outro lado, a porcentagem de primórdios necrosados nas gemas da cv. Bartlett foi significativamente superior a das gemas da cv. Shinseiki.

MONTESINOS \& VILARDELL (1991) relataram que na Espanha, há diferenças de incidência da abortamento floral entre cultivares de pereira. Diferenças entre cultivares quanto à intensidade de abortamento, também foram observados no Brasil (HERTER $\boldsymbol{e t} \boldsymbol{a l} .$, 1995), e entre cultivares asiáticos na Nova Zelândia (KINGSTON et al., 1990). HERTER et al. (1995) relataram que a cv. Packham's Triumph apresentou os maiores índices de abortamento floral, em quatro anos de observação (1989-1992). Nos cultivares asiáticos, segundo os mesmos autores, foi observada uma grande variação na incidência do abortamento floral nos diferentes anos.

Quanto ao fator local, observou-se que a porcentagem média de primórdios necrosados nas gemas dos cinco cultivares, procedentes de Veranópolis $(20,84 \%)$ foi maior do que as das gemas procedentes de Vacaria $(13,25 \%)$. A incidência do abortamento é variável e pode ser aumentada tanto por fatores climáticos como de manejo (MONTESINOS \& VILARDELL, 1991). Essa maior porcentagem de primórdios florais necrosados em Veranópolis, possivelmente, esteja ligada a fatores climáticas como temperatura, ocorrência da seca, incidência de doenças, que tenham causado mais desfolhamento precoce em Veranópolis do que Vaca- ria. O Macrozoneamento Agroecológico e Econômico do Rio Grande do Sul (Secretaria da Agricultura e Abastecimento, 1994) caracteriza esses dois municípios como regiões climáticas diferentes. Além disso, sabe-se que há diferença no tipo de solo dos dois municípios.

CAMELATTO (1992) salienta que, de acordo com trabalhos de outros países, temperaturas relativamente altas durante o final de inverno e no início da primavera reduzem a disponibilidade de carboidratos para as flores e para o crescimento de pequenas frutas de macieira, uma vez que altas temperaturas aumentam a taxa respiratória durante esses períodos e, portanto, consomem uma grande parte dessas reservas. Suspeita-se que esse período de calor possa aumentar o abortamento de gemas florais, considerando que grande parte das reservas seria retirada dos órgãos internos das gemas e ramos. Porém, MARODIN et al. (1997) não encontraram diferenças na intensidade de necrose dos primórdios provenientes de locais diferentes em que o ocorrem número de horas de frio diferentes, para a pereira cv. Packham's Triumph. Por outro lado, Veranópolis possui clima mais quente do que Vacaria.

Com relação ao parâmetro época, a maior porcentagem média geral dos cinco cultivares, quanto a primórdios necrosados, foi encontrada nas gemas da coleta realizada em 25 de junho com $17,93 \%$ de primórdios necrosados (figura 2). A segunda época de coleta (03 de junho) apresentou média geral para todos s cultivares de $8,58 \%$ dos primórdios necrosados e a primeira época (23 de abril) de $2,48 \%$. Todas as épocas diferiram significativamente, quanto à intensidade de necrose de primórdios florais.

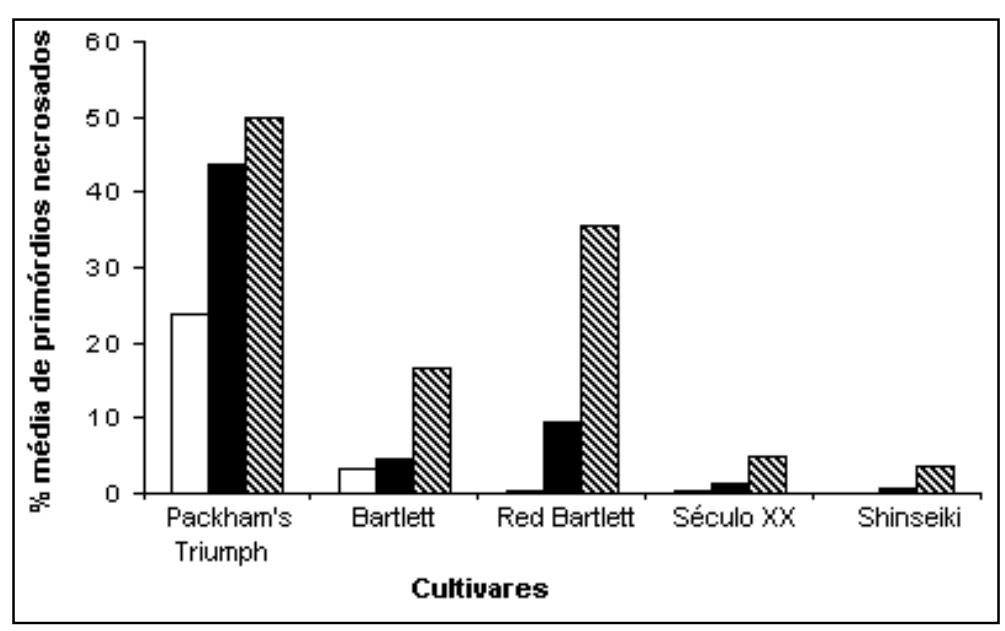

Figura 02 - Porcentagem de primórdios necrosados, para cultivares em três épocas, Vacaria e Veranópolis. 
A observação da ocorrência de primórdios florais necrosados nas gemas coletadas em 23 de abril e em 03 de junho, demonstra que o problema de abortamento inicia antes do inverno. A cv. Packham's Triumph apresentou 23,83\% de primórdios necrosados na primeira época (23 de abril) e de $43,69 \%$ na segunda época (03 de junho), o que significa que há um considerável percentual de gemas florais abortadas antes do inverno (durante a fase vegetativa e no final desta, respectivamente).

A maior percentagem de primórdios necrosados verificada no inverno (terceira época, 25 de junho), significa que há progressão na morte de gemas durante o inverno. Entretanto, isso não caracteriza que os fatores que causam o abortamento atuem continuamente desde o outono, podendo inclusive, ser o resultado de fatos ocorridos antes da referida estação. Por outro lado, não se pode descartar, que também fatores climáticas hibernais contribuam para o agravamento do abortamento das gemas florais.

\section{CONCLUSÕES}

- O abortamento de gemas florais de pereira, varia de intensidade de acordo com cultivar, sendo a cv. Packham's Triumph a mais afetada;

- ocorre maior porcentagem de abortamento de gemas florais em Veranópolis do que em Vacaria para os cultivares: Packham's Triumph, Bartlett, Red Bartlett, Shinseiki, Século XX;

- o abortamento de gemas florais da pereira inicia antes do inverno;

- há uma progressão na porcentagem de gemas florais afetadas pelo abortamento durante o período de abril a junho.

\section{REFERÊNCIAS BIBLIOGRÁFICAS}

ARRUDA, J.J.P. de, Efeitos de desfolhamento precoce, deficiência hídrica, cultivar e local, no abortamento de gemas florais da pereira (Pyrus communis, $L$.). Pelotas-RS, 1998. 43 p. Dissertação (Mestrado em Fruticultura de Clima Temperado) - Curso de Pós-graduação em Agronomia, Universidade Federal de Pelotas, 1998.

CAMELATTO, D., ARRUDA, J.J.P. de, NACHTIGALL, G.R. Abortamento de gemas florais da pereira (Pyrus communis, L.) cvs. Packham's Triumph e William's Bon Chretien. In CONGRESSO BRASILEIRO DE FISIOLOGIA VEGETAL 6, 10 a 15 ago 1997, Belém - PA. Resumos... Belém: Sociedade Brasileira de Fisiologia Vegetal, 1997. 620 p. p. 485 .

CAMELATTO, D. The relationship between fruit set of apple and carbohidrate content of bark and flower cluster base tissues., East Lansing, 1992. 198 p. Dissertation (for the degree of PhD). Michigan State University, 1992.

HERTER, F.G., CAMELATTO, D., NAKASU, B.H., $\boldsymbol{e} \boldsymbol{t} \boldsymbol{a l}$. Incidência de abortamento floral em cultivares de pereira, no Rio Grande do Sul. In: REUNIÃO TÉCNICA DE FRUTICULTURA 4, 29-30 nov. 1995, Porto Alegre-RS. Anais... Porto Alegre: FEPAGRO, 1995. 165 p. p. 95-97.

KINGSTON, C.M., KLINAC, D.J., VAN EPENHUIJEN, C.W. Floral bud disorders of nashi (Pyrus serotina) grown in New Zealand. New Zealand Journal of Crop and Horticultural Science, New Zealand, v. 18, p. 157-59, 1990.

KLINAC, D.J., GEDDES, B. Incidence and severity of the floral bud disorder "budjump", on nashi (Pyrus serotina) grown in the Waikato region of New Zealand. New Zealand Journal of Crop and Horticultural Science, New Zealand, v. 23, n. 2, p. $185-90,1995$

MAIA, M.L., AMARO, A.A., GONÇALVES, J.S., $\boldsymbol{e}$ t $\boldsymbol{a l}$ Produção e mercado de pêra e pêssego no Brasil. Informações Econômicas, São Paulo, v. 26, n. 2, p. 33-48, 1996.

MARODIN, G.A.B.; ILHA, L.L.H.; SEIBERT, E. Evalución del abortamiento de yemas florales y de la producción de pera (Pyrus communis L.) cv. Packham's Triumph en Eldorado do Sul, Estado del Rio Grande do Sul. In: CONGRESSO BRASILEIRO DE FRUTICULTURA 14, 20-25 out 1996, Curitiba-PR. Anais... Londrina: IAPAR, 1996. 561 p. p. 492.

MARODIN, G.A.B., KOLLER, O.C., BERGAMASCHI, H., et al. Abortamento de gemas florais de pereira Packham's Triumph na região sul do Brasil. In: REUNIÃO DE INTEGRAÇÃO PESQUISA X ENSINO DO CPACT 1, 5-6 jun 1997, Pelotas-RS. Anais... Pelotas: EMBRAPA/CPACT, 1997. 68 p. p. 46.

MONTESINOS, E., VILARDELL, P. Nuevos avances en el control de la necrosis de yemas de flor en el peral. Fruticultura Profesional: Peral II, Madrid, n. 40, p. 14-20, 1991.

MONTESINOS, E., VILARDELL, P. La necrosis de yemas de flor en el peral. Una enfermedad de etiologia compleja y difícil control. Fruticultura Profesional: Peral II, Madrid, n. 78, p. 88-93, 1996.

NAKASU, B.H., HERTER, F.G., LEITE, D.L., et al. Pear flower bud abortion in southern Brazil. In: INTERNATIONAL HORTICULTURAL CONGRESS 24, 21-27 ago. 1994 Kyoto, Japan. Annals... Kyoto: ActaHorticulturae, 1995, 395 p. p. 185-192.

NAKASU, B.H., LEITE, D.L. Indicação de porta-enxerto e cultivares de pereira para o Sul do Brasil. HortiSul, Pelotas, v. 1 , n. 2 , p. $20-24,1990$.

NAKASU, B.H., LEITE, D.L. Pirus 9 - Seleção de pereira para o Sul do Brasil. HortiSul, Pelotas, v. 2, n. 3, p. 19-20, ago. 1992.

SECRETARIA DA AGRICULTURA E ABASTECIMENTO / RS. Macrozoneamento agroecológico e econômico do estado do Rio Grande do Sul. Porto Alegre, Centro Nacional da Pesquisa do Trigo, 1994. 307 p. 